\title{
Call for Papers: ASSAY and Drug Development Technologies
}

Editor-in-Chief: Bruce Melancon, PhD; Vanderbilt Center for Neuroscience Drug Discovery, Franklin, TN, USA

ASSAY and Drug Development Technologies focuses on early-stage screening techniques and tools that optimize the identification of novel leads and targets for new drug development, running the spectrum from nanotechnology through cellular imaging. Case studies are presented, and technology applications are extensive. Articles published in the Journal emphasize methodologies and technologies to accelerate drug discovery.

Benefits of submitting include:

- Fast and user-friendly electronic submission

- Rapid peer review and publication

- A diversity of article types

- Maximum exposure: readership in more than 170 countries worldwide

- Competitive Author Benefits Program

$\checkmark$ Open access options available

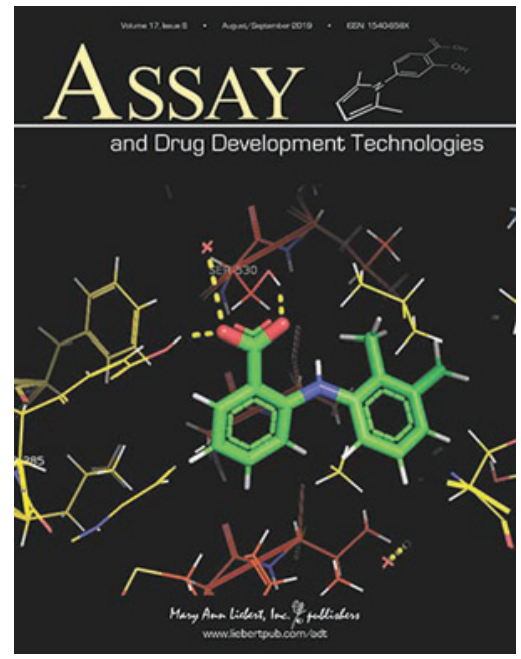

For complete author instructions and to submit your manuscript, please visit: liebertpub.com/manuscript/adt

\author{
Visit the Instructions for Authors: \\ www.liebertpub.com/adt
}

\section{Submit your paper for peer review online: https://mc.manuscriptcentral.com/adt}

